\title{
Underground Built Heritage as catalyser for Community Valorisation
}

\author{
Underground4value
}

Giuseppe PACE, ISMed-CNR, Italy

\begin{abstract}
This paper is about how framing an innovative approach for community empowerment by organising networks and consortia for preparing proposals in different research programme frameworks. In the beginning, there was as study for classifying underground spaces and using them as a solution for a sustainable over ground urban development. By advancing in the proposals preparation, the team developed a completely different vision. The underground space was more and more seen as a place for building local identity and sense of belonging, progressing from a functional to a cultural value, from a site conservation to a community valorisation approach, by giving centrality to the people and their needs. As first step, the project faced the challenge of regenerating urban areas by realising Underground Built Heritage potential for local communities and experimenting a methodological approach on sustainability transition. Just like a story, the paper describes the evolution of the approaches, and the implementation of the activities, also if unsuccessful in the competition. The consortium grew and matured, a network based on strong analysis and revision, whose members developed an impressive social capital and learned by any failure. Piece by piece, this network was able to achieve the success, and to start a COST Action, the CA 18110 "Underground Built Heritage as catalyser for Community Valorisation". The Action, funded for establishing and implementing an expert network, promotes balanced and sustainable approaches to preserve the Underground Built Heritage (UBH) and, at the same time, to realise the potential of the underground space in urban and rural areas for regeneration policies. The paper finally explains how a wellmotivated group of people can transform a network activity, with a little budget, in a research and on field project and how such a network can provide innovative tools for engaging and empowering local communities.
\end{abstract}

\section{Keywords}

Underground Built Heritage, Community empowerment, Transition Management, Sustainability

\section{Introduction}

This should be a dissemination paper of COST Action, the CA 18110 "Underground Built Heritage as catalyser for Community Valorisation". Although just started, this action has already a very interesting story to share. It is about the process of cross-fertilisation developed through its maturation process, consisting of several proposals in different EU frameworks. All these proposals had the underground space as the common starting point. In the beginning, there was an international research group focused on the underground 
space, investigating it from different perspectives, such as history, geology, conservation, and valorisation, and trying to define different aspects of the cavities, by providing functional classifications, conservation/valorisation case studies, and visualisation technologies. Local experiences were analysed mainly in terms of underground spaces' sustainable reuse for solving over-ground urban problems, sometimes from a heritageconservationism perspective, and rarely from the local communities' perspectives, not properly illustrating or explaining decision-making processes, as well as local specifications and characteristics, or the local needs as drivers of change. That was the state when a Horizon 2020 call, the SC5-21-2016 (Cultural heritage as a driver for sustainable growth: Heritage-led urban regeneration), was published. Since that moment, a small team of experts started to imagine how local communities could be engaged and involved in the urban first, and then rural, regeneration processes catalysed by the existence of underground heritage, and how that heritage could contribute to individual and collective identity, social cohesion and inclusion (Applejuice Consultants, 2008; Dodd and Sandell, 2001). Usually, heritage-led urban regeneration initiatives aim at integrating cultural heritage buildings into urban regeneration schemes for generating popular, successful urban quarters with character, where people enjoy living, and also engender economic development through job creations and influence social issues such as crime, health, education and particularly social capital (Roberts and Sykes, 2000; Evans and Shaw, 2004). What could it happen if the building are underground and/or impossible to use in a traditional way, or if it is still largely unexplored? Could the symbolic value be enough for developing community identity and regeneration? What kind of meaning should be built?

\section{Pioneering the concept}

\subsection{CUBRe 1: Culture of Underground Built Environment as a driver for urban Regeneration}

Supported by the certainty of the underground heritage's historical and cultural outstanding value, the team started to deal with the specific challenges and goals of the topic SC5-212016, such as:

- mapping, analysing and documenting successful heritage-led regeneration models;

- assisting communities through provision of expertise, advice and capacity building in developing and implementing during the life of the project their heritage-led regeneration plans;

- setting up a robust monitoring scheme to monitor the communities performances;

- developing methodologies to enable replication and up-scaling of heritage-led urban regeneration projects in different contexts;

- identifying regulatory, economic and technical barriers;

- establishing long-term sustainable data platforms securing open, consistent data

Behind the slogan of an underground heritage "...not just a challenge, but also a valuable resource to celebrate, protect and use", that first proposal was thinking at a balanced and sustainable methodology to support the conservation of the heritage and, at the same time, to realise the potential of its spaces for 'replicable' regeneration policies in urban areas. The main project challenge was engaging local communities in the preservation of the 
underground historic fabric by empowering them with adequate cultural, scientific and technical knowledge and then revitalising the public realm and developing skills for townspeople. To fertilise such a behavioural change, the team adapted an approach never used in the cultural heritage sector: the Transition Management (TM). The TM is a tool for stimulating, developing and supporting real-life experiments (Living Labs) in a goaloriented modulation, aimed at shaping processes of co-evolution and co-creation (Kemp et al., 2005). It allows communities to explore alternative social trajectories in an adaptive, forward-looking manner, combining the capacity to adapt to change with the capacity to shape change (Rammel et al. 2004) and is concerned with positive goals, collectively chosen by the community following a process of problem structuration. The team contacted, invited and involved new partners in the proposal preparation, especially institutes with competencies in planning and ICT. Considering the starting point, the project did a good progress in terms of problem understanding, but missed maturity in the activities and, especially, a structured knowledge base: the platform. In addition, many partners were not enough focused on the community and more interested to study the heritage preservation. Finally, collective learning and dissemination tools were poorly defined and not enough innovative in respect of the challenge.

\subsection{HURN: Heritage-Led Underground Regeneration Network}

That first experience made possible applying to the INTERREG Europe 2016 call. Nonetheless, the different framework asked for major changes in the objectives, activities, and partnership, which was reduced to eligible countries and public bodies. Within the scope of conserving, protecting, promoting and developing natural and cultural heritage, the call asked for improving the implementation of regional development policies and programmes in the field of the protection and development of natural and cultural heritage. The new challenge stimulated a reflective approach in the team, which fixed as main goal to establish, implement and exploit a platform for sharing best practices on the sustainable use of the Underground Heritage. Therefore, the activities were focused on collecting partners' best practices on governance mechanisms, planning framework, stakeholders' involvement management, financing mechanisms, technical needs, and their direct impacts on the underground heritage preservation, environment, society and economy, as well as potential negative externalities (i.e. 'gentrification', hardbranding, mass tourism, recreational villages, underground degradation...). The collected information, then, was the knowledge basis for a platform, open and accessible to all parties interested in the underground regeneration. The Platform could manage data, providing knowledge on main technical and organisational barriers to the underground regeneration and correlated solutions, and analysing new potential functions, seen as evolution of the historical ones - with a particular attention to their divulgation - maintaining a conservative approach of their historical value as part of the European Cultural Heritage.

Each involved region (Basilicata, Apulia, Flanders, Valencia, and Cyprus) promised to produce a UBH action plan, integrating expert knowledge with local, institutional, and market knowledge, gathering needs from local/regional stakeholders, increasing the local communities' involvement, raising local awareness, and finally providing 
transparent and open policy recommendations to the regional authorities. However, also in that case, the platform is little more than a toolkit.

\section{Maturing concept, tools and consortium}

\subsection{The workshop "Underground Cultural Heritage as a driver for Regeneration. Strengthening local and regional participation in European programs"}

The two unsuccessful proposals promoted a moment of reflection and suggested an enlargement of the potential partnership. Supported by Unioncamere Campania and Enterprise Europe Network, the CNR team organised a workshop in Naples (November $8-9^{\text {th }}, 2016$ ) with four session and a final round table to discuss about the future challenges. Participants' enthusiasm and intense debates reinforced the network and gave new impetus to the team for developing new proposals in EU funding programmes, such as Horizon 2020, INTERREG Europe, and COST.

Partners from Slovenia, Spain, Moldovia, Belgium, Cyprus, Russia, Turkey, and Georgia, contributed with theoretical, methodological, technical studies and several case studies dealing with: a) conservation and monitoring of the $\mathrm{UBH} ; \mathrm{b}$ ) valorisation policies (from urban regeneration to sustainable tourism); c) planning approaches for integrating bottom up initiatives in regional policies; and d) case studies and potential follow-ups. In particular, the CNR prepared a detailed analysis of future EU calls on Cultural Heritage, in order to reconsider the potential of the Underground Built Heritage in that framework. At that time, success rate for Cultural Heritage calls was incredibly low in $\mathrm{H} 2020$ (2.1\%), and definitely higher in Interreg Europe (20.5\%). The meeting, in addition, provided a first clarification about innovative planning approaches for community empowerment, such as Strategic Stakeholders' dialogue (SSD) (Van Tulder et al 2004) and Transition Management (TM) (Kemp at al. 2005). In addition, I started proposing their integration into a new tool, the Strategic Transition Management (STM), based on local communities' experiments and empowerment, and a multi-level strategic dialogue (e.g. Living Labs) (Pace, 2018). Finally, the meeting pointed out the need for a better support from the ICT private sector and a more extended network of countries. Naples workshop provided the seeds for the future proposal success: the wide and voluntary participation and the development of a common understanding created a right momentum for the following challenges.

\subsection{CUBRe 2: Conservation of the Underground Built heritage as catalyser for rural Regeneration}

The second CUBRe proposal represents the big change in the approach. Designed for participating to the topic SC5-21-2017 "Cultural heritage as a driver for sustainable growth: Heritage-led rural regeneration", it deals with if and how could Underground Built Heritage support rural development initiatives. All main national and supra-national programmes (Agenda 21; EU Objective 1, 5b and LEADER schemes), as well as rural regeneration studies (Edwards et al, 2000; Pretty, 1998; Shucksmith, 2000; Hodge \& Midmore, 2008; Brown, 2010; Scott, 2012; EDORA, 2013; Juppenlatz, 2015) placed emphasis on two correlated 
concepts, endogenous development and partnership. Both of them place the community participation at the centre of the rural regeneration process. The first in terms of stakeholders' capacity of mobilising local actors and resources, the second in terms of changing governance practices by empowering local people in rural areas and involving them in the planning process through 'bottom-up' approaches. CUBRe objective was to answer two main needs for rural regeneration: establishing community participation and drawing local resources. The UBH was that local resource, by lying at the heart of people' sense of place and contributing to individual and collective identity, social cohesion and inclusion. However, CUBRe portraits the UBH as a resource largely unexplored, even not documented, and indeed under-utilised, whose conservation depends on local public bodies with different organisational and legal frameworks and, often, lacking of technological capabilities and financial resources.

The proposal maintains the previous CUBRe approach of community engagement, but greatly implemented the platform, the Underground Heritage Platform (UHP), and better specifies the connections between the project, the platform and the living labs. In particular, the UHP develops two capacity-building activities: knowledge meetups and knowledge consultancy. The first shares cumulated knowledge through innovative and highly participative in-person and digital knowledge sharing meetups. To build capacity in the living lab, UHP establishes exchange and feedback with relevant stakeholders and other peers that lead to replication and knowledge sharing. It develops online learning tools, visualisation, technical guidance and production to help establishing and institutionalising a knowledgesharing framework, combined with specialised on-site training events. It also includes participatory online webinars with more practical guidance and exchange.

Knowledge consultancies are tailored and targeted for each replicator needs. A usergenerated needs model ensures direct involvement of replicators and their stakeholders into the process, providing them with advice and coaching. The Platform becomes the central product of the project and is tested, implemented and managed throughout the entire project life. Designed to support different public and private stakeholders, it uses open source software and develops flexible and accessible tools, by exploiting the latest mobile application technologies and solutions, which maximize its services usability, effectiveness and dissemination. Outcomes are a common understanding and awareness of the issues at stake, mobilization of local knowledge, joint problem ownership, and co-creation of solutions, that is, a better basis for decision-making.

Finally, CUBRe developed an innovative and effective communication and dissemination strategy, based on the "Role Models" success-stories storytelling and a wide local campaigning for activating a favourable environment from both social and economic point of view. The communication would sustain a vision of the underground heritage as a positive economic resource and a crucial element for recovering individual and collective identity, and building social inclusion and cohesion, which better supports Living Labs creation and increases the willingness of local communities to co-create rural regeneration plans.

Established in order to achieve a disciplinary complementarity, coherent with the project knowledge needs, the consortium included a very dedicated group of professionals, public officials, and academics from eight EU and three EU associated countries. Among partners, there were six universities, four research institutes with expertise in applied research, four private companies with relevant expertise in communication, business services, monitoring 
and informatics, three city councils, two regional development agency, and seven non-profit organisations.

The proposal was among the four (on 42) that successfully passed to the H2020 Stage 1 . The evaluation recognised the interactive, open-source digital platform, as a multifunctional tool for research, education, dissemination as well as a symbolic and innovative mechanism of local empowerment. In Stage 2, the project ranked second and first of the reserve list, but was not funded. Although unsuccessful, the proposal was fundamental milestone for working on UBH at the community level.

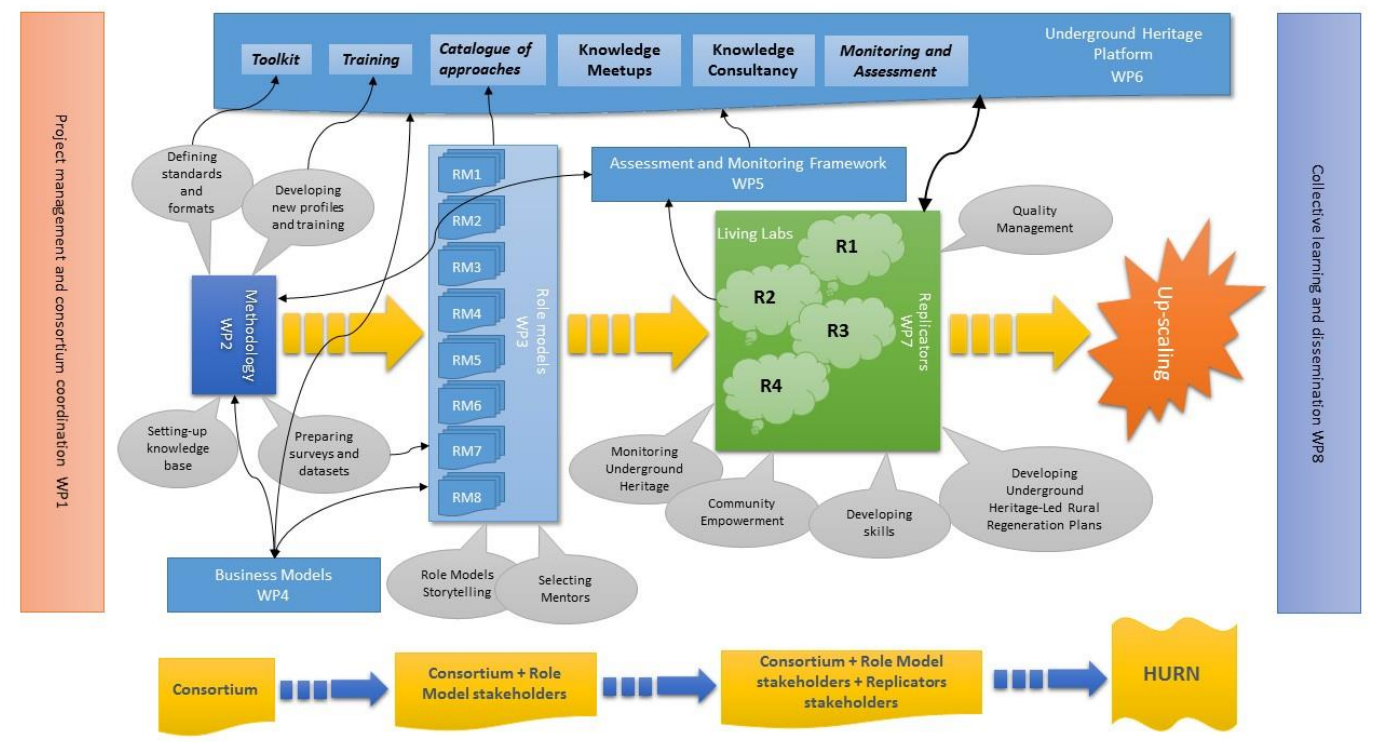

Figure 1 Overall CUBRe Logical Building Blocks and Work packages

\subsection{HURN 2: Heritage-Led Underground Regeneration Network}

The subsequent challenge was the INTERREG Europe call 2017. The specific objective was "Improving natural and cultural heritage policies" and the proposal represented a relevant progress from the previous 2016. With the participation of seven organisations from Italy, Spain, Slovenia and Belgium, the proposal addressed the implementation of the Operational Programmes ERDF 2014-2020 for Sardinia and Murcia regions, the Operational Programme for the Implementation of the EU Cohesion Policy 2014-2020 in Slovenia, and the Marketing strategy 2016 - 2020 for Tourism Flanders.

With the scope of fostering regional policies for a sustainable approach to the UBH, this second HURN proposal defined the following goals:

- Collecting the good practices and making them available to active and passive users, by disseminating cultural, scientific and technical knowledge on UBH, and by setting up a catalogue of approaches and context-specific practices for the "Environment \& resource efficiency platform"

- Applying a Strategic Dialogue approach, by engaging key stakeholders in the involved regions, for formulating and implementing UBH valorisation strategies 
- Producing an UBH action plan for each concerned region, which integrates expert knowledge with local, institutional, and market knowledge, gathers needs from local/regional stakeholders, increases local communities' involvement, raises local awareness, and provides transparent and open policy recommendations to the regional authorities.

- Seeding a stable European Heritage-Led Underground Regeneration Network (EHURN), with a well-defined and ambitious communication strategy.

The action decided to develop a powerful and well-experimented communication and dissemination support to the project by adding a Telematic University to the consortium. That would facilitate the knowledge transmission between HURN scientific and institutional partners, as well as with the local and international stakeholders. By using those technological tools, knowledge could be collected and analysed, as well as a catalogue of approaches produced and context-specific practices directly linked to the Programme platform. In addition, it would also make available the HURN toolkit and training facilities, and set up monitoring tools for all policy instrument implementation. In that proposal, for the first time, the Strategic Dialogue (SD) 8-step model (Van den Berg and Pietersma, 2014) was adapted to the UBH specific objectives. Unluckily, for a missing partner electronic signature, the proposal was not retained for the evaluation and the team acquired little learning from that experience.

\section{The COST ACTION “Underground Built Heritage as catalyser for Community Valorisation"}

\subsection{The first proposal 2016}

The COST (European Cooperation in Science and Technology) Association, established in 1971, is an International not-for-profit Association under Belgian Law, which has currently 39 Member countries, and manages the COST programme. Its mission is to enable breakthrough scientific and technological developments leading to new concepts and products and thereby contribute to strengthening Europe's research and innovation capacities. It allows researchers, engineers and scholars to jointly develop their own ideas and take new initiatives across all fields of science and technology, while promoting multi- and interdisciplinary approaches. COST aims at fostering a better integration of less researchintensive countries to the knowledge hubs of the European Research Area. In the beginning, it was not $100 \%$ clear how to use the COST networking tools for developing a pure on-field innovative action. However, maybe a networking approach could make UBH-led community engagement more understandable. Under that perspective, the first Underground4value saw the light. The main challenge was to promote a sustainable use of the UBH, by integrating policies and practices of conservation into the wider goals of regional and local development, in respect of the inherited values and traditions of different cultural contexts.

The proposal was mainly focused on solving the conflict between underground heritage and underground space. It stated that current physical planning approaches under-perform in dealing with Cultural Heritage, and specifically with UBH. There is a rising awareness that physical approaches can only be part of the solution to communities' problems, and that planners should better "...address how people mix and connect, their motivations, and whether they 'own' where they live" (Bianchini, 1999). In addition, planning tools must 
stimulate and facilitate local communities' empowerment, by connecting natural, social, cultural, political and economic environments, gauging impacts across different spheres of life, and grasping the importance not only of 'hard' but also of 'soft' infrastructures" (Bianchini, 1999). The transition of the proposal centrality from the built heritage to the individual and the community was then completed.

The proposal was positively evaluated (55 on 65 ) but not retained for funding. Why? The evaluation was very clear. It defined the topic as relevant, but rather an "evergreen" issue, which can always be considered as timely, and therefore not extremely urgent to solve. Were they right? How could we change their mind?

\subsection{The second proposal 2018: CA18110 “Underground Built Heritage as catalyser for Community Valorisation"}

Those two questions were at the centre of the proposal redesign in the 2018 COST proposal collection. Even if the new proposal does not appear so different, its centre is not anymore the Underground Built Heritage, but its value for the community and the society. Therefore, it is a value "to celebrate and preserve and when sustainable, to re-use and valorise, realising its full potential to support local communities' development" (see http://underground4value.eu/). The centre becomes now how the community can use this value in terms of sustainability challenge, a value that can catalyse urban/rural regeneration and attract tourism, raise community awareness and make local communities more resilient to globalised systems of production and consumption by preserving their unique environmental and cultural aspects. The sustainability challenge is certainty timely, as well as actions supporting the transition towards sustainability, by promoting changes in interdependent societal systems and across multiple scales - from the supply chains to the communities and individual citizens' behaviours and values - through complex and uncertain processes, mainly depending on experimentation, learning and sharing ideas. The proposal, also if difficult to experiment only in an expert network, opens the way to develop areas for experimenting and managing the transition. Activities seek for acquiring and testing tools to encourage dialogue and engage stakeholders across society in order "to determine where we need to go and how we are going to get there" (EEA 2016). Past experiences and the network composition provide relevant knowledge about tools for stimulating and facilitating local communities' empowerment and connecting natural, social, cultural, political and economic environments. They are the Strategic Stakeholder Dialogue (SSD) and the Transition Management (TM), eventually integrated into a new tool, the Strategic Transition Management (STM). The proposal defines as a new objective to "...pioneering socially and environmentally innovative solutions, by stimulating, developing and supporting processes of local community co-evolution and co-creation, which allows communities to explore alternative social trajectories in an adaptive, forward-looking manner, such as the Strategic Transition Management (STM)" (Underground4value, 2018).

The proposal was retained with a score 63 on 65 , and admitted to funding. Since April $9^{\text {th }}$ is active as COST Action 18110, and put together experts of 25 countries. The most innovative component is the new annual organisation of the activities, which are less and less of pure and open networking, and more and more part of a structured project (Figure 2).

The Management Committee selects four case-studies. Then, three thematic working groups - Underground Built Heritage conservation and monitoring (WG2); Underground Built 
Heritage reuse and valorisation strategies (WG3); Underground Built Heritage planning approaches (WG4) - and two methodological and organizational ones - Knowledge Base Development (WG1); Dissemination and exploitation strategies (WG5) - prepare knowledge base contents and assessment tools for analysing case-studies. Small teams of participants perform yearly four case-study assessments, by using the Short-Term Scientific Missions (STSMs) tool.

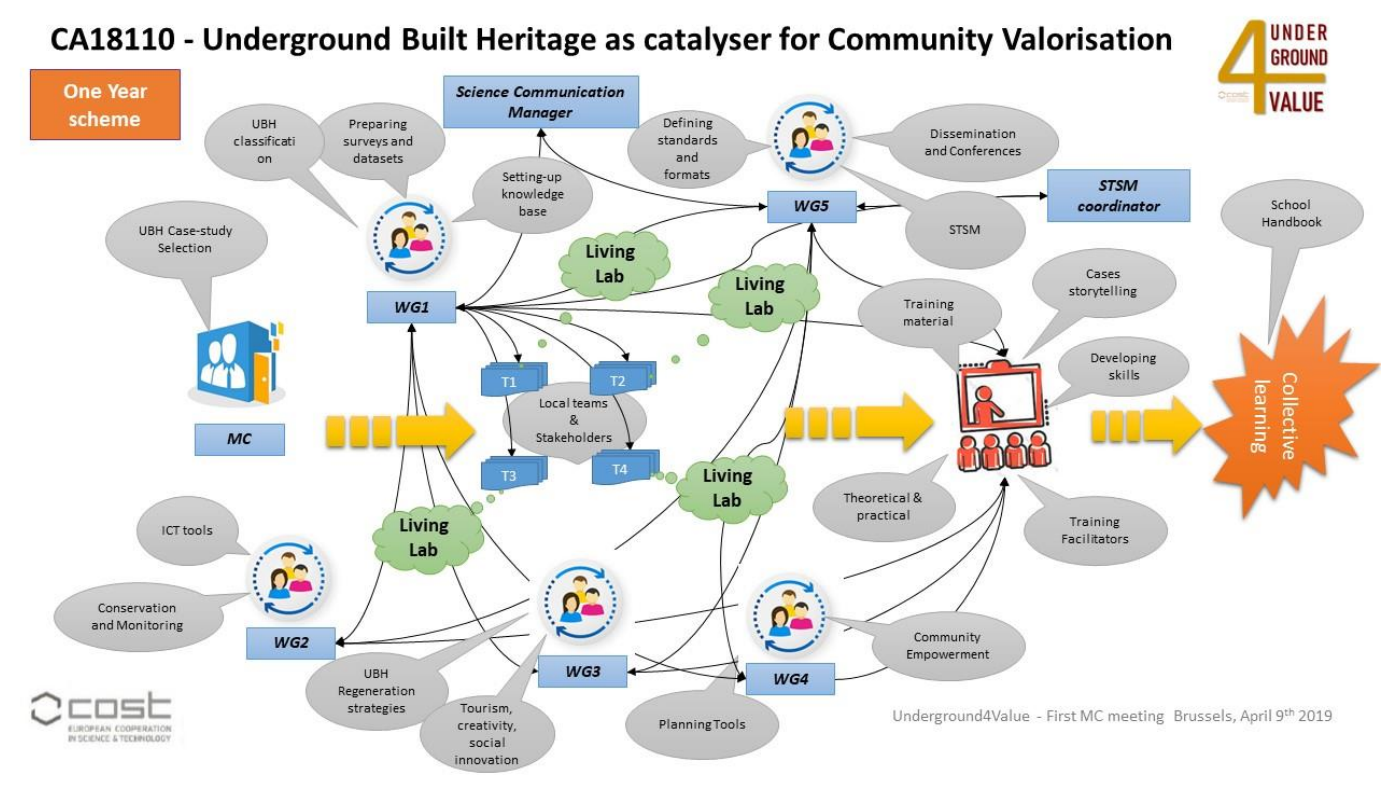

Figure 2 COST 18110 one-year action scheme

These assessments, jointly conducted by an external participant, together a local team, aims at developing a living lab approach on a specific UBH-based topic. Since the first meeting, the network developed a shared definition of living lab, that is, innovative actions experimented and implemented in real communities (a neighbourhood, a city, a region), but sheltered by adequate scientific and technical knowledge, technological capabilities and financial resources.

That approach would open to interacting with local communities, disseminating innovative thinking and supporting them to explore alternative social trajectories in an adaptive, forward-looking manner. Results will be discussed and analysed during workshops and, specifically, at the training courses, where trainers and trainees will work together on specific topics, producing a yearly publication.

The first year case studies are Naples (IT), Postojna (SI), La Union (ES), Göreme - Cappadocia (TR) (Figure 3).

The Action is an Expert network with the scope to become a structured and stable voluntary association for sharing research experience, best practices and ideas on UBH. A platform approach will support the creation of a repository for new research and for developing training tools, open and accessible to all parties interested to the UBH. Platform and tools will provide knowledge on main technical and organisational barriers to the UBH conservation and reuse. This knowledge will be the basis for:

- promoting continuity of use and significance to the underground historic fabric, revitalizing the public realm and developing skills for townspeople 
- Assisting local communities' decision-making with cultural, scientific and technical support from many aspects (i.e. archaeology, geo-technics, history, urban planning, cultural anthropology, economics, architecture, cultural tourism).

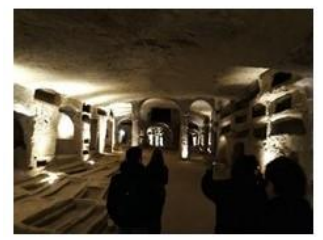

Naples (IT): Modern Age tuff quarries under one of the most crowded urban areas of the world, with about 800 caves, 3000 water cisterns, $180 \mathrm{~km}$ of aqueducts' tunnels, catacombs, cemeteries, tombs, air-raid shelters, partially used as touristic attraction and partially reconverted into transport infrastructure

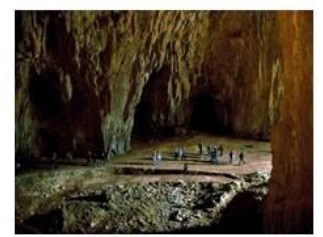

Postojna (SI): Three underground natural caves located on the classical Karst, which represent a significant case study as historical example of regeneration and valorisation since visitors' information centre and tours date back to 17th century. It is also one of the first examples of underground best practice in architecture hosting a post office and a multiservice space for visitors.

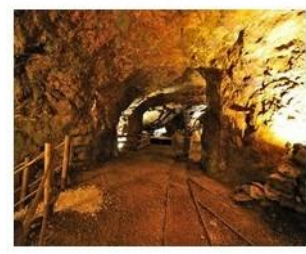

La Unión (ES): Mining caves since the time of Romanized-lberian settlements, they have been transformed in a successful touristic destination. An exemplary site of abandoned caves and their valorisation as significant signs of local rural cultural heritage. The introduction of flamenco dance performances and music exhibitions are the most innovative approaches to re-functionalisation

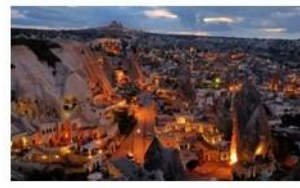

Göreme - Cappadocia (TR): Located on the central Anatolia plateau, the region is set in a moonlike landscape of giant rock cones, housing historic cave-dwellings and Byzantine churches. Added to the World Heritage List by UNESCO in 1985, it offers a sustainable balance between heritage conservation, cultural tourism development and local community empowerment, thanks to many successful regeneration interventions.

Figure 3 COST 18110 first year case studies

Obviously, the new Action is only at the beginning, but the enthusiasm showed by the participants at the first Working Group meeting in Ancona (June 6-7 $7^{\text {th }}, 2019$ ), as well as the interest of the local stakeholders, demonstrated the high potential of the concept and its replicability. The case study phase, with the expert assessment and the living lab establishment, will give a clear measure of the action potential, which will benefit from the reflective event of the training school.

The school is specifically organised with the purpose of developing new forms of training for planners. During the training school, outcomes of working groups and case-studies will be tested and validated. In addition, organised stakeholders' conferences will act as a vehicle for networking, public engagement, dissemination, knowledge sharing and exchange of best practice and innovative concepts and ideas for future developments and joint ventures. Specifically when surveying the gaps in underground built heritage, the Action will seek engagement with local communities' leaders, professional associations, privates, universities, SMEs in Cultural Heritage, experienced professionals and other stakeholders. Senior research associates, members of local policymaking bodies and associations, experts in cultural heritage research, will be invited to contribute to the Action's activities and events, and benefit from the Action's outcome. 


\section{References}

Applejuice Consultants (2008), Social impact of Heritage Lottery Funded projects. Evaluation report on research conducted for the Heritage Lottery Fund during 2006-2007.

Bianchini F. (1999), "Cultural planning for urban sustainability", in Nystrom L., Fudge C. eds. Culture and Cities. Cultural Processes and Urban Sustainability, Stockholm, pp. 34-51

Dodd J. and Sandell R. (2001), Including Museums: Perspectives on Museums, Galleries and Social Inclusion, Research Centre for Museums and Galleries.

EDORA, European Development Opportunities for Rural Areas (2011), Final Report, ESPON

Edwards WJ et al (2000) Partnership working in rural regeneration: governance and empowerment? Policy Press, Bristol.

Evans $G$ and Shaw $P$ (2004), The contribution of culture to regeneration in the UK: a review of evidence. London Metropolitan University, London.

Hodge I \& Midmore P (2008), 'Models of Rural Development and Approaches To Analysis Evaluation And Decision-Making', Économie rurale, 307

Juppenlatz, E. (2015), Rural Regeneration and Localism: A case study of Northumberland, PhD Thesis, University of Newcastle

Kemp R, Rotmans J (2005), 'The management of the co-evolution of technical, environmental and social systems', Weber M, Hemmelskamp J (eds.), Towards Environmental Innovation Systems, Springer Verlag.

Pace G (2018), Planning Approaches for Heritage-led Community Development", in Genovese L, Yan H, Quattrocchi A, (eds) Preserving, Managing, and Enhancing the Archaeological Sites: Comparative Perspectives between China and Italy, pp 163-172.

Pretty J (1998), The Living Land. Agriculture, Food and Community Regeneration in Rural Europe, Earthscan, London

Rammel C et al. (2004), Governing Sustainable Development. A Co-evolutionary Perspective on Transitions and Change, GoSD working paper 1.

Roberts P and Sykes H (2000), Current challenges and future prospects, in Roberts P., Sykes H. eds., Urban regeneration: a handbook. Sage publications, London, pp. 295-314.

Scott, A. (2012) Partnerships: Pandora's Box or panacea for rural development? Working Paper Series, no. 11, Birmingham University

Shucksmith, M. (2000), Exclusive countryside? Social inclusion and regeneration in rural areas, Joseph Rowntree Foundation

Van den Berg G and Pietersma P (2014), The 8 Steps to Strategic Success: Unleashing the Power of Engagement, Kogan Page, London.

Van Tulder R. et al (2004), De Strategische Stakeholderdialoog. Opkomst, sussesfactoren en toekomst, Erasmus University 